Family Profile No. 20, 2021

\title{
Recent Marriages to Same-sex and Different-sex Couples: Mobility, Region, Home Ownership, and Household Income
}

Authors: Krista K. Payne \& Wendy D. Manning

In 2015, a U.S. Supreme Court landmark decision ensured that everywhere in the nation, same-sex couples had the legal right to marry. Thanks to revised household roster data, analyses of newly married same-sex and different-sex couples are possible for the first time with the 2019 American Community Survey (ACS). We examine differentials in key geographic and economic indicators (mobility, geographic residence, homeownership, and household income) for newly married couples. A focus on newlywed couples, rather than all married couples, provides insights into their circumstances at the time of marriage. Other recent Profiles on newlyweds include Recent Marriages to Same-sex and Different-sex Couples (ㅍ-19-21) and Median Age at First Marriage for Samesex and Different-sex Couples, 2019 (FP-21-11). This profile uses data from the ACS 1-year PUMS files from 2019 to examine individuals who married in the last year disaggregated by the sex/gender composition of the marriage entered into. Analyses are limited to currently married householders and spouses of householders who married in the last year, and we show $95 \%$ confidence intervals in some figures. Note that the sequencing cannot be determined for marriage, moves, residence, and homeownership within the last year.

\section{Marriages and Moves in the Last Year by Gender Composition of the Couple}

\section{Recent Marriages}

- Based on the ACS, there were about 35,000 marriages to female same-sex couples and 29,000 to male samesex couples, along with nearly 1.7 million marriages to different-sex couples in 2019.

- About $2.0 \%$ of marriages in 2019 were to female samesex couples and $1.7 \%$ were to male same-sex couples. The share of recent marriages to female same-sex couples was significantly larger than the share to male same-sex couples $(p<.05)$.

Figure 1. Gender Composition of Recently Married Couples, 2019

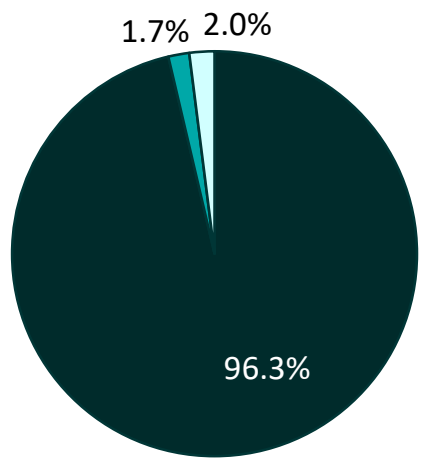

\section{Movers}

- Newlyweds in different-sex couple relationships were more like to have moved in the last year than newlyweds in same-sex couple relationships.

- Over one-in-three different-sex newlyweds moved in the last year.

- Similar shares of male and female same-sex newlyweds moved in the last year, $18 \%$ and $22 \%$, respectively.

Figure 2. Movers by Gender Composition of Recently Married Couples, 2019

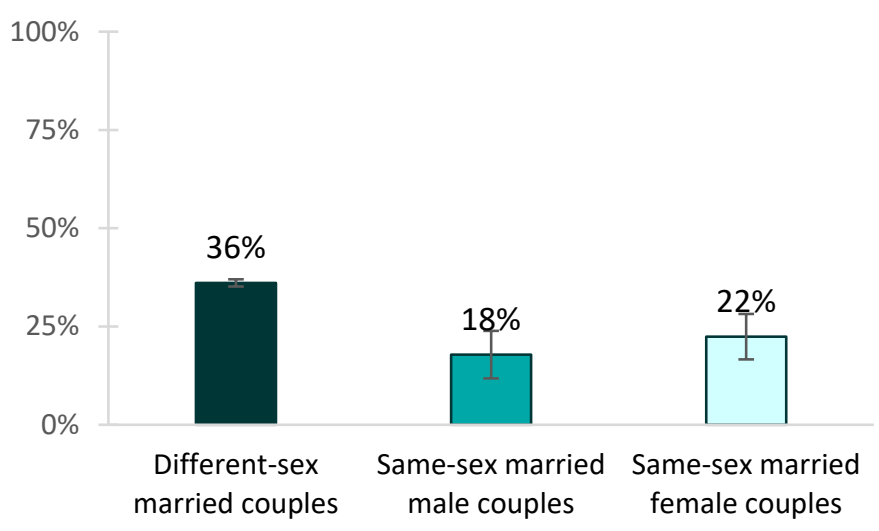

Note: We cannot distinguish the timing of the move and marriage so some moves may have occurred prior to marriage and others after marriage. We report the share who reported they married and moved in the last year.

Source: NCFMR calculations of the American Community Survey 1-year estimates, 2019 


\section{Where are they living now? Region of Current Residence and Recently Married Couples}

- More newlyweds (about two in five) lived in the South than any other region, and this holds true for same-sex and different-sex couples.

- A smaller share of recently married male same-sex couples lived in the Midwest (15\%) than opposite-sex or female same-sex couples.

- A smaller share of recently married female same-sex couples lived in the Northeast than male same-sex couples.
Figure 3. Region of Residence by Gender Composition of Recently Married Couples, 2019

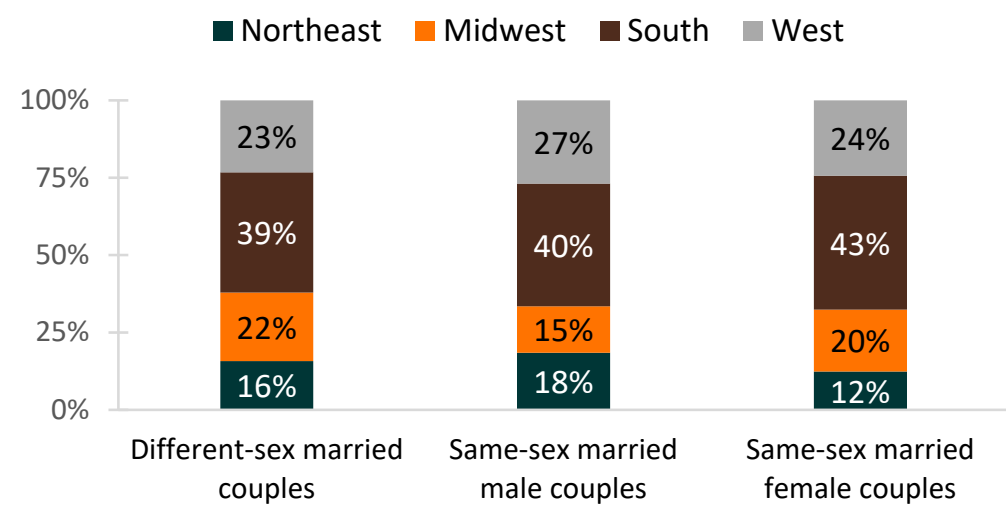

Note: There is not a significant difference between the share of same-sex married male couples and same-sex married female couples within any of the four regions of the U.S.

Source: NCFMR calculations of the American Community Survey 1-year estimates, 2019

\section{Homeownership and Household Income Among Recently Married Couples}

- About half of all newlyweds are homeowners regardless of the gender composition of their marriage.

- Despite similar homeownership among recently married couples, median household income varies significantly by the gender composition of the couple.

0 The highest household income was found among men who recently married men. At an average of $\$ 147,000$ a year, this is significantly higher than men and women who recently entered into a marriage with a different-sex spouse $(\$ 107,000)$ and women who recently entered into a marriage with a same-sex spouse $(\$ 96,000)$.

$\circ$ The average household income among different-sex couples who married in the last year was also significantly higher than the household income of female same-sex couples who married in the last year $(p<0.05)$.

Figure 4. Homeowners by Gender Composition of Recently Married Couples, 2019

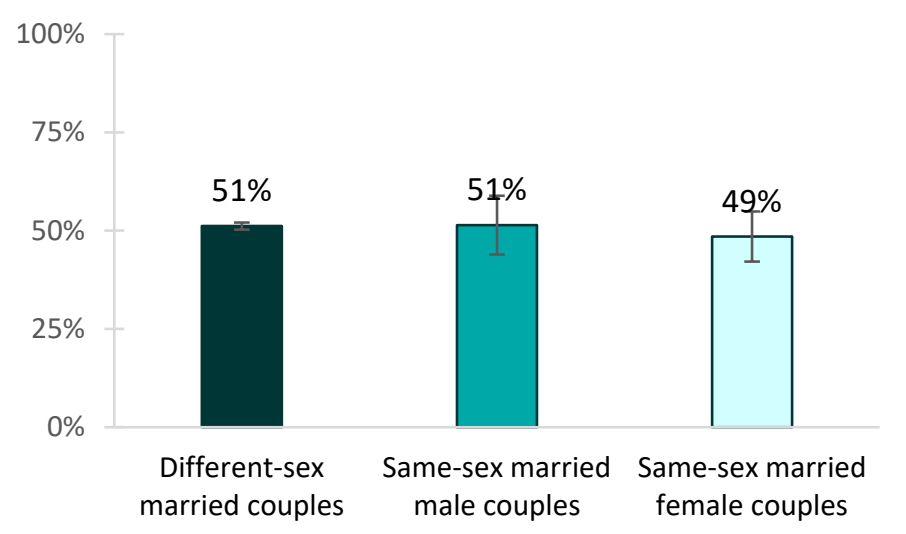

Figure 5. Mean Household Income by Gender Composition of Recently Married Couples, 2019

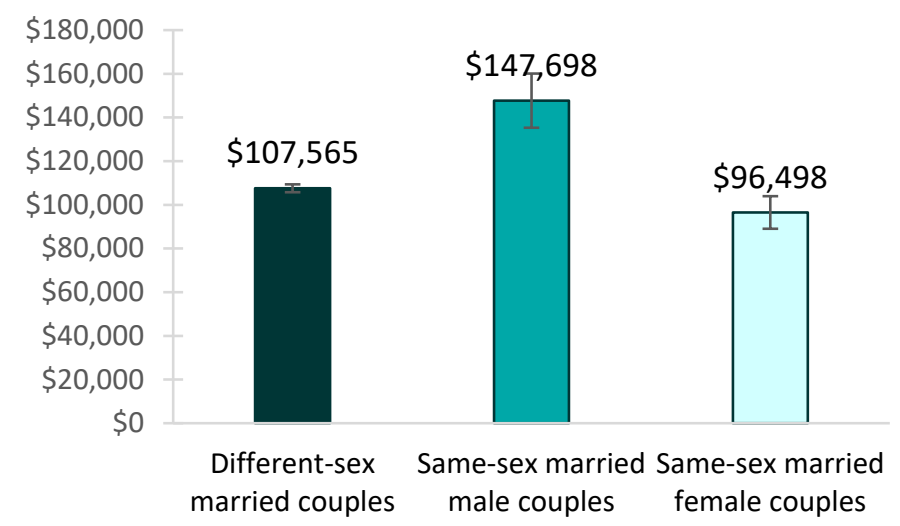

Source: NCFMR calculations of the American Community Survey 1-year estimates, 2019

\section{Data Source:}

U.S. Census Bureau, American Community Survey, 1-year estimates, 2019.

\section{Suggested Citation:}

Payne, K. K. \& Manning, W. D. (2021). Recent marriages to same-sex and different-sex couples: Mobility, region, home ownership, and household income. Family Profiles, FP-21-20. Bowling Green, OH: National Center for Family \& Marriage Research. 